\title{
THE APPLICATION OF LIFE CYCLE COST (LCC) APPROACH TO QUALITY FOOD PRODUCTION: A COMPARATIVE ANALYSIS IN THE PARMA PDO HAM SECTOR
}

\author{
Mattia Iotti and Giuseppe Bonazzi \\ Department of Civil Engineering, Environment, Territory and Architecture (DICATeA), \\ University of Parma, Parma, Italy
}

Received 2014-06-10; Revised 2014-06-23; Accepted 2014-07-05

\begin{abstract}
In the international literature, the subject of the analysis of the cost of production is often confined to the analysis of short-term convenience. However, the quantification of the cost of production per unit of product has a particular importance in the processing enterprises, especially in the initial phase of choice that concerns realization of investments in facilities and technologies to improve productivity. About this general theme, the research applies the Life-Cycle Cost (LCC) approach to quantify the cost of production in the long-term operation in the processing of pig meat in the Parma PDO ham sector. The research considers not only the analysis of a single good or service such as a plant or a building, which is what frequently appears in LCC application, but also the quantification of the cost of an industrial production, in its whole cycle, during a long-run period. The research applies the LCC approach to a sector with high capital intensity for a typical food production. In the research, the application of the LCC shows that innovative firms that have made investments to improve business efficiency, have lower production cost in the long run; these firms are able to gain efficiency in the production cycle, as result of the investments made to reduce production costs, calculated applying LCC approasch. It then can be stated that the LCC approach represents a useful tool for analysis of convenience-cycle management of companies not only in the short period but even in the long run, particularly those operating in sectors with high capital intensity and with a long payback period of investments in fixed capital, as considered in the research. Moreover, it could be useful to deep the analysis applying the suggested LCC approach to a larger sample, even in other sector, to verify the usefulness of the LCC application in quantifying whole life cost.
\end{abstract}

Keywords: Life-Cycle Cost (LCC) Analysis, Activity Based Costing (ABC), Parma PDO Ham, Meat Processing Firms

\section{INTRODUCTION}

In Italy, the meat sector is characterized by the herd of heavy pig that is bred to be processed for typical Italian cold cuts production, especially the typical ham (PDO ham), for these hams use fresh legs of pigs born, raised and slaughtered in a defined area and the pigs must have characteristics of quality defined in specific production rules. The firms operating in the agro-food system that produce food with long aging periods have to face problems related to the high level of capital requirement; often, the firms have difficulties relating to the duration of the financial cycle because the firms require large investments in start-up activity for the acquisition of industrial buildings, plants and equipment. Parma ham is the most important production sector of Italian cold cuts. It is a Protected Designation of Origin (PDO) ham; protected by the legislation of the European University of Parma, Parma, Italy 
Union on designations of origin, prosciutto di Parma DOP (Parma PDO ham) is a product of high quality, consumed and appreciated in Italy and worldwide for production specification and productive tradition. Parma PDO ham firms, as agri-food firms, often have to face problems related to the high level of capital requirement; often, the firms have difficulties relating to the duration of the financial cycle because the firms require large investments in start-up activity for the acquisition of industrial buildings, plants and equipment (Iotti and Bonazzi, 2014), even if this is more frequent incase of cooperative firms (Bonazzi and Iotti, 2014); moreover, the capital requirement is inherent with the typical production aging period, which requires large volumes of capital, then expands the capital requirement for equipment. In fact, the cycle of aging of the fresh meat causes further expansion of capital requirements in order to sustain the cycle of working capital. Considering the channel of sales frequently used by firms in the sector, namely large-scale Distribution (GDO) it is to note an increase in average day extensions in receiving payment from customers and this aspect of financial dynamics improves the capital requirement for processing firms. Parma PDO ham, in fact, has very high production costs not only for the purchase of fresh pork of high quality but also for the process of transformation of the pork leg into seasoned prosciutto. In fact, to ensure the high quality of the finished product, the Parma PDO Ham Consortium has adopted strict production disciplinary guidelines governing the various aspects of production and limiting the discretion of the choices of firms in reducing costs. Calculating the cost of production in enterprises of Parma ham is not sufficient to analyze the costs of production in the short term. Sector businesses, in fact, often made significant investments in industrial plants with a high component of industrial buildings and installations; these investments should be evaluated throughout the course of their useful life in order to calculate the cost of production of Parma PDO ham, taking into account all long-term costs.

This analysis, however, is not always possible. We must therefore have the availability of corporate data in the long term for a series of at least 10 years; you also need enterprise data, including investments made, production that was carried out in terms of fresh meat processed by weight (in kilograms) and the details of the costs incurred, divided by kind, also dividing between fixed costs and variable costs. In addition, companies in the sector of Parma ham often differ in size of the company or the organization of production; from this point of view, it can be seen that there are two types of enterprises most frequently found in the sector. In the Parma PDO ham sector, craft-and family-owned firms operate, flanked by large firms with more capital investments that can develop an annual production volume of more than 200,000 hams. The first type of firm is characterized by its smaller size and generally has a connection between ownership and control; the second type is characterized by its greater size and, in some cases, operates in corporate groups and has easier access to credit and an equity capital market. The traditional firms have production plants with overlapping areas of processing and aging of fresh meat on more than one floor of the factory, which is often not modernized. The sector also has operating firms that have made investments in properties, plants and equipment to increase the efficiency of production; these firms are typically characterized by membership in large groups or operations with higher production volumes and, on a larger scale, with advantages in terms of reducing the unit cost of production. In general, all the firms in the sector are characterized by a long aging period and then having to face problems related to the high level of capital required.

\section{MATERIAL AND METHODS}

Many researchers are interested in analyzing the revenues and costs over time in order to quantify the profitability of the company, dividing costs into fixed and variable (Atkinson and Kaplan, 1998; Boer, 1974; Cooper and Kaplan, 1992). It is possible to proceed with the analysis of revenues and costs in a generic period ( $t$ ), analyzing the level of profit ( $\mathrm{tt}$ ) expressed as the difference between Total Revenue (TRt) and Total Cost (TCt); total costs are equal to the sum of the Fixed Costs $(\mathrm{FCt})$ and Variable Cost (VCt) Equation 1:

$\Pi_{t}=T R_{t}-T C_{t}=T R_{t}-\left(V C_{t}+F C_{t}\right)$

We can detail the approach considering the total amount of finished goods produced (Q) as the sum of the quantities produced by the company for each finished product $(j), j: j \in[1, J$ Equation 2 :

$Q_{t}=\sum_{j=1}^{J} q_{j}$ 
It is therefore possible to express the total revenue from the sale of the whole of the finished products, considering the price per unit $(p)$ of finished product $(j)$, $j: j \in[1, J]$ Equation 3 :

$$
T R_{t}=p_{1} q_{l}+\ldots+p_{J} q_{J}=\sum_{j=1}^{J} p_{j} q_{j}
$$

It is the possible to calculate the average selling price for the finished product $(A p j)$ Equation 4:

$$
A p_{j}=\frac{R T_{t}}{Q_{t}}
$$

To deepen the analysis of the costs, we consider that Fixed Costs (FC) are, by definition, invariant with respect to the level of production in the short term, whereas the Variable Costs (VC) are given by the sum of the Variable costs per unit $(\mathrm{Vc})$ for each unit of finished product (j), $\mathrm{j}: \mathrm{j} \in[1, \mathrm{~J}]$ Equation 5:

$$
V C_{t}=V c_{1} q_{1}+\ldots+V c_{J} q_{J}=\sum_{j=1}^{J} V c_{j} q_{j}
$$

It is therefore possible to express the Total Cost (TC) as follows:

$$
T C_{t}=\sum_{j=1}^{J} V c_{j} q_{j}+F C_{t}
$$

From Equation 6, we can derive the formulation of the Average unit Cost (ACt) as Equation 7:

$$
A C t_{t}=\frac{\sum_{j=1}^{J} V c_{j} q_{j}+F C_{t}}{Q_{t}}
$$

The analysis for revenue and costs emerges, in the first place, as the convenience to the realization of the investment (in a one-period optical restricted to the period t) is detected in the condition of equilibrium, for which the profit assumes a positive sign (Пt) Equation 8:

$$
T R_{t}-\left(V C_{t}+F C_{t}\right)>0 P \Pi_{t}>0
$$

The cost analysis, which allows for a split between fixed costs and variable costs, gives rise to two approaches (direct costing and full costing) as evidenced by a large number of researchers over time (Al Omiri and Drury, 2007; Costa and Guzzo, 2013; Debnath and Bose, 2014; Cooper and Kaplan, 1999; Pong and Mitchell, 2006). The direct costing assigns only the costs directly attributable to the individual productions, while overhead costs are not allocated and are briefly summarized at the close of the reclassified income statement. On the other hand, the full costing is attributed to individual productions' portion of all costs of the company and also includes a portion of overhead costs (Bjornenak, 1997; Cardinaels et al., 2004; Cobb et al., 1993; Dolinsky and Vollman, 1991; Drury and Tayles, 2005), applying one or more cost drivers. At the end of the charges, all firms' costs are segmented between the different productions. In detail, the method of direct costing is developed according to a marginal approach, for which the profit is maximized when the condition that marginal revenue equals marginal cost occurs. The methodology of direct costing has the advantage of achieving the objective quantification of the cost of production while giving only specific costs. It is therefore a methodology that features increased reliability, while omitting the attribution of a share of overhead costs and aims to provide management with more information about the relationship between the volume of production and profit (Cooper and Kaplan, 1999). An essential element for the direct costing is the concept of Contribution Margin (CMt), defined as the difference between Total Revenue (TRt) and Variable Cost (VCt) Equation 9:

$C M_{t}=\sum_{j=1}^{J} p_{j} q_{j}-\sum_{j=1}^{J} V c_{j} q_{j}=T R_{t}-V C_{t}$

The contribution margin highlights the contribution of a product to cover the fixed costs and the formation of net income; the contribution margin per unit of product is given by the difference between unit revenue (or value of production per unit) and unit variable cost. In the event that the contribution margin per unit of output is greater than zero, the sale price can cover variable costs and contribute to covering fixed costs, so production is sustainable. Conversely, if the contribution margin is negative, the selling price is not able to cover the variable costs of inputs used, so the production is not sustainable (each unit of product offered for sale generates a loss). The cost accounting approaches, such as direct costing and full costing, have, however, been criticized because they do not fit correctly in identifying the causal relationships of absorption of the factors of 
production, in particular, in case of increasing organizational complexity of companies, organized by processes (Kaplan, 1988). The core problem of the traditional accounting system is the indirect cost allocations that are generally allocated based on the direct labor cost and sometimes on direct material cost. Activity-Based Costing ( $\mathrm{ABC}$ ) is currently overcoming traditional cost accounting approaches and many researchers have discussed the superiority of $\mathrm{ABC}$ over traditional accounting systems (Argyris and Kaplan, 1994; Cooper, 1990; Cooper and Kaplan, 1991, 1992; Shim and Stagliano, 1997; Yoshikawa et al., 1994), even if applied to public sector firms (Vazakidis et al., 2010). At the same time, the method could be applied in an ex ante approach, applying estimation methods, as Kolmogorov's forward equations method (El-Said, 2008). The approach of the cost of production in a single year is not suitable for evaluating the long-term investment and the costs in the long run. In fact, it is necessary to consider the cost of production for the total life of the investment, proceeding according to the technique of ABC (Artto, 1994; Asiedu and Gu, 1998; Askarany and Smith, 2003; Fabrycky and Blanchard, 1991; Tysseland, 2008). It has therefore the importance of applying the $\mathrm{ABC}$ approach in the long run with the Life-Cycle Costing (LCC) approach. This approach takes into account all costs of operations, discounting the cost items, being particularly relevant to evaluate investments in capital-intensive firms, with significant presence of investment in buildings and plants, whose return on investment is in the long-run period. In addition, the LCC approach is considered of great importance for firms characterized by a high level of quality of production or, in the analysis of business efficiency, in terms of long-term quality (Hedeşiu et al., 2012; Kallunki and Silvola, 2008; Korpi and Ala-Risku, 2008; Schiffauerova and Dale, 2006; Srivastava, 2008), also taking into consideration aspects of the impact of the business social system and environment (Mizsey et al., 2009; Solli and Reenaas, 2009). This is the situation of companies in the Parma PDO ham sector that are often characterized by high investments in property and equipment. About the assessment of convenience to the realization of an investment in the long run, as in equipment, building, or machinery, it must be taken into account the effects that this may generate for the complexity of its useful life $(\omega)$ or for a predetermined time horizon, defined as partial time horizon $(\psi)$, such that $\omega>\psi, \psi$ and $\omega$ expressed in years. This distinction on the duration of the analysis distinguishes approaches aimed at quantifying the convenience to the realization of the investment in which there is reference to only a part of the useful life during a certain time horizon $(\psi<\omega$ as mentioned); we can define this as "partial approaches"; if the analysis has reference to the complex life of the investment $(\omega)$, we talk of "global approaches." In both the approaches, in the partial as well as in the overall approach, it is possible to refer to a variety of types of flows; if the analysis considers cost flow, we develop an LCC approach. The LCC approach aims to quantify the absorption of resources in the production process, by hypothesis, all over the life cycle of the investment. This approach is developed in particular for those investments analyzed according to an approach of the production function of the type input/output and, therefore, for investments that, compared with an absorption of resources in the course of the total useful life, such as factors of production, produce output not necessarily expressed, in whole or in part, by currency, such as an environmental production. The methodology allows for taking into account the emissions and the use of resources absorbed for the production in a given good, throughout the useful life of this, from the extraction of resources until the end of its use. LCC assesses the total cost of a system or product over its entire life span. Other researchers (Norris, 2001; Shapiro, 2001) can consider how it can also be developed for an approach that privileges a noneconomic analysis of the effects resulting from the implementation of an investment, expressed, for example, in physical units, until the end of the investment's useful life, according to the methodology called Life-Cycle Assessment (LCA). This approach is particularly useful when it is necessary to analyze aspects of environmental impact (Dimitrios and Aristomenis, 2005; Vijaya et al., 2009). LCC compares the cost-effectiveness of alternative investments or business decisions from the perspective of an economic decision maker, such as a manufacturing firm or a consumer (Norris, 2001). Where there is, therefore, the usefulness of evaluating an investment in the long term, having reference to the whole of the useful life of the investment, life-cycle analysis or LCC is useful for carrying out evaluations of costs, taking into account all of the life cycle of the investment (for example, a building, plant and machinery), thus allowing for deepening, also aiming to assess alternative investments, then quantifying alternative investments associated with the minimum payment in terms of absorption of resources. This approach has regard not for an instantaneous time, or a partial period of time, but considers the whole of the useful life of the investment. We consider, as several researchers did (Rebitzer and Seuring, 2003; Rebitzer and Hunkeler, 2004), first, the costs of the project and construction of the building, that is, the costs incurred during the start-up of the investment, herein referred to 
as $\mathrm{CI}_{\mathrm{B}}$, as the sum of project Cost at year zero $\left(\mathrm{CP}_{\mathrm{B}}\right)$ and Construction Cost at year zero $\left(\mathrm{CC}_{\mathrm{B}}\right)$ :

$C I_{B}=C P_{B}+C C_{B}$

It is then indicated as follows: the cost related to the management of the building expressed on an annual basis, with years from 1 to $\omega$, expressing time horizon as $\omega$. The cost of building Management $\left(\mathrm{CM}_{\mathrm{B}}\right)$ for a single generic year $\mathrm{t}, \mathrm{t}: \mathrm{t} \in[0, \omega]$, is expressed as follows Equation 11:

$$
C M_{B}=C M e_{B}+C M m_{B}+I C_{B}+C M o_{B}
$$

We can then express $\mathrm{CMe}_{\mathrm{Bt}}$ as energy costs of the building in a generic $t, t: t \in[1, \omega] ; \mathrm{CMm}_{\mathrm{Bt}}$ is cost of maintenance of the building; $\mathrm{IC}_{\mathrm{Bt}}$ is interest charge; and $\mathrm{CMo}_{\mathrm{Bt}}$ is other costs of the building; expressing for a year generic $t, t: t \in[1, \omega]$, we have Equation 12:

$$
C M e_{B}=\sum_{e=1}^{E} C m e_{B e}
$$

where, $\mathrm{Cme}_{\mathrm{Be}}$ is a single item of cost for energy. Also, we have Equation 13:

$$
C M m_{B}=\sum_{m=1}^{M} C m m_{B m}
$$

W where $\mathrm{Cmm}_{\mathrm{Bm}}$ is a single item of cost for maintenance. Finally, we have Equation 14:

$$
C M o_{B}=\sum_{o=1}^{O} C m o_{B o}
$$

where, $\mathrm{Cmo}_{\mathrm{Bo}}$ is a single item of other cost. Thus, the annual cost of management is expressed as the sum of three row vectors, $\mathrm{CMe} 1, \mathrm{E}=\langle\mathrm{Cme} 1,1 \ldots \mathrm{Cme} 1, \mathrm{M}\rangle$, $\mathrm{CMm} 1, \mathrm{M}=\langle\mathrm{Cmm} 1,1 \ldots \mathrm{Cmm} 1, \mathrm{M}>, \mathrm{CMo} 1, \mathrm{O}=$ $<\mathrm{Cmo} 1,1 \ldots \mathrm{Cmo} 1, \mathrm{O}>$, expressing with $\mathrm{E}, \mathrm{M}$ and $\mathrm{O}$, respectively, the number of individual cost items for the categories of costs for Energy (E), Maintenance (M) and general cost (O) that have to be calculated $\forall \mathrm{t}$, $\mathrm{t}: \mathrm{t} \in[1, \omega]$. The model of the life cycle can also consider (Artto, 1994) any gain or loss arising from the disposal of the building or its eventual redevelopment as the following terminal value Equation 15:

$\Pi_{B}^{\omega}=R d_{B}^{\omega}-C d_{B}^{\omega}$

where, $\Pi_{B}{ }^{\omega}$ is profit of disposal of the building at the time horizon $\omega, R d_{B}{ }^{\omega}$ is revenues of disposal of the building at the time horizon $\omega$ and $C d_{B}{ }^{\omega}$ is costs of disposal of the building at the time horizon $\omega$. It is then possible to determine the total cost resulting from LCC, discounting cash outflow during the whole useful life of the investment as follows:

$$
T C_{B}{ }^{\omega}=C I_{B}+\sum_{t=1}^{\omega} \frac{C M_{B t}}{(1+i)^{t}}-\frac{\Pi_{B}{ }^{\omega}}{(1+i)^{\omega}}
$$

where, $T C_{B}{ }^{\omega}$ is total discounted cost and $\mathrm{i}$ is the discount rate. In the case in which the period of the project and construction covers several years, it is appropriate to proceed to the actualization of the relative initial Charges of Investment $\left(\mathrm{CI}_{\mathrm{B}}\right)$, not more sustained only in the initial year, as set in Equation 10, but Supported along a time (S) greater than a one-year period. We then express Equation 16 as follows Equation 17:

$T C_{B}{ }^{\omega}=\sum_{\mathrm{t}=1}^{S} \frac{C I_{B t}}{(1+i)^{t}}+\sum_{t=S+1}^{\omega} \frac{C M_{B t}}{(1+i)^{t}}-\frac{\Pi_{B}{ }^{\omega}}{(1+i)^{\omega}}$

In order to apply the LCC analysis of a manufacturing facility, it is desirable to extend the analysis set out above by analyzing the initial investment costs of the plant, distinguishing between fixed costs and variable costs. To this end, it could be useful to distinguish between costs independent of the level of production, that is, Fixed Costs (FC) and costs dependent of the level of production, or Variable Costs (VC). LCC could even consider (Iotti and Bonazzi, 2007; Rabino and Wright, 1993), as the first element, the costs of the project and construction of the plant (i.e., the costs incurred in the start-up of the plant Investment $\left(\mathrm{CI}_{\mathrm{P}}\right)$ ). We have project Cost at year zero $\left(\mathrm{CP}_{\mathrm{P}}\right)$ and Construction Cost at year zero (CCP) Equation 18:

$$
C I_{P}=C P_{P}+C C_{P}
$$

It is therefore possible to express the cost of production in relation to the quantity of production expressed in physical units (q), $q$ : $q \in\left[0, Q_{\max }\right]$ for $a$ 
generic year $(t), t: t \in[1, \omega]$, expressing $Q_{\max }$ as the maximum production level of the plant. We aim to quantify the Total Cost of Plant management (TCP) for a given year $(\mathrm{t})$ Equation 19:

$$
T C_{P t}=V C_{P t}+F C_{P t}=V c_{P t} \times q_{t}+F C_{P t}+I C_{P t}
$$

For a generic year $(\mathrm{t}), \mathrm{t}: \mathrm{t} \in[1, \mathrm{~m}], \mathrm{VCP}$ are plant management variable costs, $\mathrm{Vc}_{\mathrm{P}}$ are plant management variable costs per unit of product, $\mathrm{FC}_{\mathrm{P}}$ are plant management fixed costs; financial charges of plant management $\left(\mathrm{IC}_{\mathrm{p}}\right)$ are considered separately; $\mathrm{q}$ is the processed quantity, $\mathrm{q}: \mathrm{q} \in\left[0, \mathrm{Q}_{\max }\right]$. We can consider also any gain or loss arising from the disposal of the plant or its eventual redevelopment Equation 20:

$\Pi_{P}{ }^{\omega}=R d_{P}{ }^{\omega}-C d_{P}{ }^{\omega}$

where, $\Pi_{P}{ }^{\omega}$ is profit of disposal of the plant at the time horizon $\omega, R d_{P}{ }^{\omega}$ is revenues of disposal of the plant at the time horizon $\omega$ and $C d_{P}{ }^{\omega}$ is costs of disposal of the plant at the time horizon $\omega$. It is then possible to apply the LCC approach to plant management as follows:

$T C_{P}{ }^{\omega}=C I_{P 0}+\sum_{t=1}^{\omega} \frac{T C_{P t}}{(1+i)^{t}}-\frac{\Pi_{P}{ }^{\omega}}{(1+i)^{\omega}}$

In Equation 21, TCp $\omega$ is the total cost of the plant discounted at the Time horizon (OT). Considering then the processing costs, always in relation to the quantity of production expressed in physical units $(q)$, $\mathrm{q}: \mathrm{q} \in\left[0, \mathrm{Q}_{\max }\right]$ for a generic year $(\mathrm{t}), \mathrm{t}: \mathrm{t} \in[1, \omega]$, we can express Equation 22:

$T C_{T t}=V C_{T t}+F C_{T t}=V c_{T t} \times q_{t}+F C_{T t}$

For a generic year $(\mathrm{t}), \mathrm{t}: \mathrm{t} \in[1, \omega], \quad \mathrm{TCT}$ is transformation processing cost, $\mathrm{VC}_{\mathrm{T}}$ is total variable cost of transformation processing, $\mathrm{Vc}_{\mathrm{T}}$ is variable cost of transformation processing per unit of product, $\mathrm{F}_{\mathrm{CT}}$ is total fixed cost of transformation processing, $\mathrm{q}$ is processed quantity $\mathrm{q}: \mathrm{q} \in\left[0, \mathrm{Q}_{\max }\right]$. We can then apply the LCC approach to processing activity as follows:

$T C_{T}{ }^{\omega}=\sum_{i=1}^{\omega} \frac{T C_{T t}}{(1+i)^{t}}$
In Equation 23, $\mathrm{TC}_{\mathrm{T}}{ }^{\omega}$ is discounted total cost of transformation for the time horizon (OT). Industrial cost is then expressed as follows:

$$
\begin{aligned}
& T C_{I}^{\omega}=C I_{P 0}+\sum_{t=1}^{\omega} \frac{T C_{P t}}{(1+i)^{t}}+\sum_{t=1}^{\omega} \frac{T C_{T t}}{(1+i)^{t}}+ \\
& +\frac{\Pi_{P}{ }^{\omega}}{(1+i)^{\omega}}=T C_{P}{ }^{\omega}+T C_{T}{ }^{\omega}
\end{aligned}
$$

In Equation 24, $\mathrm{TC}_{\mathrm{I}}{ }^{\omega}$ is industrial discounted cost at time horizon (OT). It is therefore possible to express the total cost at time horizon for the firm, applying the $\mathrm{LCC}$ approach that is, $\mathrm{TC}_{\mathrm{F}}{ }^{\omega}$ and that could be expressed as follows:

$T C_{F}{ }^{\omega}=T C_{B}{ }^{\omega}+T C_{I}{ }^{\omega}$

Equation 25 considers the total amount of the real estate Cost $\left(\mathrm{TC}_{\mathrm{B}}{ }^{\omega}\right)$ and the total amount of industrial Cost $\left(\mathrm{TC}_{\mathrm{B}}{ }^{\omega}\right)$. It is therefore possible to formulate, as follows, the average Annual Cost discounted $\left(\mathrm{ATC}_{\mathrm{F}}{ }^{\omega}\right)$ as an indicator of cost-expressive absorption of monetary resources per unit of time, according to an LCC approach:

$A T C_{F}{ }^{\omega}=\frac{T C_{F}{ }^{\omega}}{\omega}$

On the basis of Equation 26, it is then possible to assess the economic convenience to the realization of an investment industrial processing activity, considering a whole concept of cost, discounted from the beginning to the time horizon of the investment. This approach considers absorption of costs by placing in comparison the average Annual Cost discounted $\left(\mathrm{ATC}_{\mathrm{F}}{ }^{\omega}\right)$ of different alternatives of investment and defining as optimal and therefore preferable, from the economic point of view, the alternative characterized by less monetary resource absorption.

\section{RESULTS}

The aim of the work is to compare the cost of production of two types of firms operating in the sector of Parma PDO ham. The first type is made up of traditional companies that have made few investments in property and equipment; these firms are often working in manufacturing plants a few decades old and use a lot of 
manpower. The second type of firm consists of modern enterprises that have made investments in property and equipment to reduce the use of manpower; these firms often work in modern factories and, however, sometimes pay high borrowing costs, having recourse to bank loans to finance investment. In the article, we have used data from two companies. The first firm (A) is a traditional firm, while the second firm (B) is a modern firm as defined previously. The research developed in the article is therefore considered the analysis of costs in the long term by applying the approach to LCC in two cases of enterprise, of which the first (company A) is organized in a traditional plant, whereas the second (company $\mathrm{B}$ ) is organized in a modern plant and the firm has invested in real estate and technology. The objective of the research is to quantify the cost of production of these the two companies in the long run, considering the investment costs and financial charges on a time series of data of 10 years, from 2003 to 2012. At present, given the difficulty of finding corporate data about management, which are confidential and not public, it was not possible to further expand the number of companies involved in the research. In any case, the LCC approach presented here could set a method that can be developed in the future on a larger sample and even in other sectors that are characterized by a similar attention to quality issues as companies involved in the research. We have to consider that the data used in the research are confidential data that are not published in the annual account balance sheet and therefore, it is difficult to achieve the firm's data in sufficient numbers to form homogeneous firm groups to achieve statistical significance of the analysis. It must therefore carry out research on individual cases, although this certainly limits the statistical significance of the analysis made. The first firm (traditional " $\mathrm{A}$ " firm) operates in a manufacturing plant, built on four levels of processing, in 1985. A large part of the processing activities are carried out by hand, with significant industrial use of direct labor. Investments in technologies were not carried out and only the refrigeration of cold storage preservation of meat was renewed in 2003. It is a company with a modest level of technology, one which has decided not to make new investments to reduce the need for capital and to decrease borrowing costs. The company has a production capacity of 75,000 hams per year, with an average weight of $12.5 \mathrm{~kg}$ and a production capacity of approximately $937,500 \mathrm{~kg}$ per year of fresh meat. The second firm (modern "B" firm) works in a manufacturing plant built in 2003, on a single ground level of processing; the large part of the processing activities are conducted with automated machinery, with reduced use of direct industrial labor. The firm has made investments in property, plant and technologies so that the factory is totally new, both for plants and for the structures of buildings. With regard to the timing of realization of investments, they were carried out in the year of establishment of the enterprise, while the first two years of activity have been brought up to speed production potential of the company. Based on the available data, the potential of the factory is approximately 80,000 hams per year, with an average weight of $12.5 \mathrm{~kg}$ and a production capacity of approximately $1,000,000 \mathrm{~kg}$ per year of fresh pork processing starts. In view of the good initial endowment, structures were not considered to require further investment in future years, except for the maintenance of the plants built during the start-up of the firms. The investments made by the company are aimed at the innovation of the production cycle and the containment of operating costs caused by the use of technologies that allow the reduction of processing time and the waste of the finished product. The investments have made possible automating a large part of the production cycle and were partly financed with equity and partly by ignition of financing debt in the long term, in the technical form of mortgage loans. The analysis of data involved, for both companies, a series of 10 years, from 2003 to 2012 (Table 1). The traditional company (A) has made investments in the building during the reporting period and has an average operating cost of the building amounting to $€ 170,800$ per year, not discounted. The average borrowing cost is $€ 44,800$ per year because loans for the purchase of the property have not yet closed. The maintenance cost is $€ 43,200$ per year due to extraordinary maintenance carried out in 2006 and 2009.

The cost of installations, as shown in Table 2, amounted to $€ 897,200$ per year on average as a nondiscounted value. The company carried out a maintenance period on cold storage in 2003 and has not made other investments. In the management of the plant, the average variable cost is $€ 597,300$ per year, of which $€ 256,700$ is variable labor cost (production personnel assigned to facilities) with an average of seven workers employed. The average cost of fixed installations is $€ 294,200$ per year, of which $€ 139,900$ personnel costs are fixed (three technicians employed 
on average for the operation of the plant, including the charge of production).

The average cost of conversion amounted to $€ 1,341,845$ per year (nondiscounted), as shown in Table 3. In the transformation process, without considering the cost of raw materials, the average variable cost is $€ 229,800$ per year, of which $€ 60,800$ is labor cost variables (i.e., production staff, with an average of two workers employed), as well as costs for services production, including costs for services of manpower and technical expertise. The average fixed cost of transformation is $€ 213,900$ per year. The traditional company (A) has an industrial average discounted cost of $€ 1,189,728$ and an average total cost of $€ 1,341,845$. The impact of the discounted cost of the building in the 10year analysis, on each kilogram of processed meat, is equal to $€ 0.16$ per kilogram. This low incidence is given by the absence of significant investments in traditional firms first. The impact of the discounted cost of the facilities, in the 10 years of analysis, on each kilogram of fresh meat processed, is equal to $€ 0.82$ per kilogram. This incidence is determined in particular by personnel costs and the costs for the industrial services. The incidence of the cost of processing, in the 10 years of analysis, on each kilogram of processed meat, amounts to $€ 0.41$ per kilogram. The innovative firm (B) has made an investment of $€ 2,245,000$ in the building, considering cost of construction of the building and excluding the cost of land, as show in Table 4. The building has a covered area of $3,200 \mathrm{~m}^{2}$, of which $2,900 \mathrm{~m}^{2}$ is for the production and $300 \mathrm{~m}^{2}$ is for offices; the cost of the project was $€ 180,000$. The residual value of the property, assuming a useful life of 20 years, was estimated at $50 \%$ of the cost of construction in 2012. The company has contracted a loan of 10 years (floating rate) to finance the construction of the plant. The costs for borrowing have been considered in the cost of the building and account for an average of $€ 85,600$ per year. During the reporting period, the average operating costs of the building amount to $€ 138,700$ per year, not discounted; the company paid a few maintenance costs and few energy costs. In fact, the building of new construction has allowed for providing technology solutions and energy savings that have reduced energy consumption. The total cost of the building, net of $€ 1,112,500$ for terminal value, has the average of $€ 268,950$ per year. The average cost of installations amounted to $€ 606,600$ per year (nondiscounted), as shown in Table 5.
The company has made an initial investment in facilities for $€ 1,140,000$; this investment has a useful life of 10 years and has no terminal value. In the management of the plant, the average variable cost is $€ 289,500$ per year, of which $€ 130,700$ is variable cost of labor (production personnel assigned to facilities) with an average of four workers employed; the average cost of fixed installations is $€ 199,600$ per year, of which $€ 52,600$ personnel cost is fixed, considering one technical employee on average for the operation of the system that performs the functions of head of production. It can be seen that the innovative firm employs in the management of the plant less than five workers and this has been possible because of the initial investment in machinery and equipment, which allows for saving of labor. The average cost of processing amounts to $€ 1,159,680$ per year, nondiscounted, as shown in Table 6. In the transformation process, without considering the cost of raw materials, the average variable cost is $€ 220,100$ per year, of which $€ 62,200$ is personnel variable cost (i.e., production staff), at an average of two workers employed, as well as costs for services production, including costs for services of manpower and technical expertise; the average fixed cost of transformation is $€ 153,100$ per year.

The innovative firm (B) has an industrial average cost of $€ 886,673$ (discounted) and an average total cost of $€ 1,159,680$. The impact of the discounted cost of the building in the 10 years of analysis on each kilogram of meat processed is equal to $€ 0.28$ per kilogram. The impact of the discounted cost of the facilities in the 10 years of analysis on each kilogram of meat is equal to $€ 0.56$ per kilogram. This incidence is lower than company A's, even in the presence of significant investments in the year 2003. The investment in the plant, however, has allowed for a reduction in operating costs, in particular by reducing the cost of personnel. The incidence of the cost of processing amounts to $€ 0.34$ per kilogram. This incidence is lower than company A's because of lower incidence of fixed costs of transformation. At the end of the analysis, the applications of the LCC approach expresses that there are significant differences in the cost structure between the two analyzed firms. In particular, the innovative firm (B), as shown in Table 7, has better results in cost control in the long run, particularly by the decreasing of average cost of the plant. Traditional firm (A) has better performance in cost control of building, but shows a higer level of cost per $\mathrm{kg}$. of fresh meat processed $(1,38$ $€ / \mathrm{kg}$ against $1,18 € / \mathrm{kg}$ for innovative firms). 
Mattia Iotti and Giuseppe Bonazzi / American Journal of Applied Sciences 11 (9): 1492-1506, 2014

Table 1. Cost of building management (traditional "A" firm)

\begin{tabular}{|c|c|c|c|c|c|c|c|c|c|c|c|c|}
\hline \multirow[b]{2}{*}{ Cost of the building } & & \multicolumn{11}{|c|}{ Value per year in $€$ (rounded, 000 ) } \\
\hline & & 2003 & 2004 & 2005 & 2006 & 2007 & 2008 & 2009 & 2010 & 2011 & 2012 & Mean values \\
\hline \multicolumn{2}{|c|}{ Cost of the building construction } & - & - & - & - & - & - & - & - & - & - & - \\
\hline \multicolumn{2}{|c|}{$\begin{array}{l}\text { (year } 2012 \text { terminal value) } \\
\text { Cost of the project of the building- }\end{array}$} & - & - & - & - & - & - & - & - & - & - & - \\
\hline \multicolumn{2}{|l|}{ Energy cost } & 35,000 & 36,000 & 34,000 & 38,000 & 39,000 & 41,000 & 45,000 & 44,000 & 49,000 & 51,000 & 41,200 \\
\hline \multicolumn{2}{|l|}{ Maintenance cost } & 12,000 & 25,000 & 48,000 & 55,000 & 59,000 & 7,000 & 6,000 & 20,000 & - & - & 43,200 \\
\hline \multicolumn{2}{|l|}{ Interest charge } & 60,000 & 45,000 & 48,000 & 44,000 & 42,000 & 41,000 & 42,000 & 46,000 & 42,000 & 38,000 & 44,800 \\
\hline \multicolumn{2}{|l|}{ Other cost } & 65,000 & 48,000 & 51,000 & 26,000 & 39,000 & 31,000 & 29,000 & 88,000 & 24,000 & 15,000 & 41,600 \\
\hline \multicolumn{2}{|c|}{ Cost of the building management } & 72,000 & 54,000 & 81,000 & 63,000 & 79,000 & 20,000 & 22,000 & 98,000 & 15,000 & 04,000 & 170,800 \\
\hline \multicolumn{2}{|l|}{ Total cost of the building } & 72,000 & 154,000 & 181,000 & $263,000 \quad 1$ & 179,000 & 120,000 & 122,000 & 298,000 & 115,000 & 104,000 & 170,800 \\
\hline \multicolumn{13}{|c|}{ Discount rate (BTP 10 year 2003- } \\
\hline \multicolumn{2}{|l|}{2012 less infl. rate) } & $2.06 \%$ & $2.56 \%$ & $2.86 \%$ & $2.86 \%$ & $2.56 \%$ & $2.86 \%$ & $1.36 \%$ & $3.86 \%$ & $2.96 \%$ & $1.86 \%$ & - \\
\hline \multicolumn{2}{|c|}{ Total discounted cost of the building } & 172,000 & 150,156 & 171,075 & 241,666 & 161,786 & 104,219 & 12,502 & 28,601 & 91,065 & 88,105 & - \\
\hline \multicolumn{13}{|c|}{ Source: Our processing of directly collected data } \\
\hline \multirow[b]{2}{*}{ Cost of the plant } & \multicolumn{12}{|c|}{ Value per year in $€$ (rounded, 000) } \\
\hline & 2003 & 2004 & 2005 & 2006 & 2007 & 2008 & & 2009 & 2010 & 2011 & 2012 & Mean values \\
\hline Plant construction cost & 45,000 & - & - & - & - & - & & - & - & - & - & - \\
\hline Plant project cost & 12,000 & - & - & - & - & - & & - & - & - & - & - \\
\hline Energy variable cost & 45,000 & 42,000 & 43,000 & 48,000 & 19,000 & 48,00 & & 52,000 & 84,000 & 49,000 & 65,000 & 49,500 \\
\hline Labor variable cost & 180,000 & 178,000 & 190,000 & 245,000 & 250,000 & 248,0 & 000 & 290,000 & 318,000 & 320,000 & 348,000 & 256,700 \\
\hline Services variable cost & 152,000 & 156,000 & 188,000 & 165,000 & 164,000 & 125,0 & 000 & 150,000 & 135,000 & 148,000 & 149,000 & 153,200 \\
\hline Other variable cost & 85,000 & 84,000 & 102,000 & 150,000 & 164,000 & 135,0 & 000 & 170,000 & 145,000 & 164,000 & 180,000 & 137,900 \\
\hline Plant variable cost & 462,000 & 460,000 & 523,000 & 608,000 & 597,000 & 556,0 & 000 & 662,000 & 682,000 & 681,000 & 742,000 & 597,300 \\
\hline Labor fixed cost & 98,000 & 91,000 & 92,000 & 105,000 & 152,000 & 154,0 & 000 & 155,000 & 168,000 & 190,000 & 194,000 & 139,900 \\
\hline Services fixed cost & 59,000 & 94,000 & 91,000 & 92,000 & 105,000 & 108,0 & 000 & 145,000 & 132,000 & 133,000 & 109,000 & 106,800 \\
\hline Other fixed cost & 35,000 & 38,000 & 31,000 & 34,000 & 56,000 & 45,00 & & 48,000 & 57,000 & 59,000 & 54,000 & 45,700 \\
\hline Interest charge & 2,000 & 2,000 & 2,000 & 2,000 & 2,000 & 2,000 & & 2,000 & 2,000 & 1,000 & 1,000 & 1,800 \\
\hline Plant fixed cost & 194,000 & 225,000 & 216,000 & 233,000 & 315,000 & 309,0 & 000 & 350,000 & 359,000 & 383,000 & 358,000 & 294,200 \\
\hline Plant total cost & 713,000 & 685,000 & 739,000 & 841,000 & 912,000 & 865,0 & 000 & $1,012,000$ & $1,041,000$ & $1,064,000$ & $1,100,000$ & 897,200 \\
\hline $\begin{array}{l}\text { Discount rate } \\
\text { (BTP } 10 \text { year 2003- }\end{array}$ & $2.06 \%$ & $2.56 \%$ & $2.86 \%$ & $2.86 \%$ & $2.56 \%$ & $2.86 \%$ & & $1.36 \%$ & $3.86 \%$ & $2.96 \%$ & $1.86 \%$ & - \\
\hline 2012 less inflation rate) & 713,000 & 667,902 & 698,476 & 772,781 & 824,295 & 751,2 & 248 & 933,213 & 798,569 & 842,545 & 931,879 & - \\
\hline
\end{tabular}

Source: Our processing of directly collected data

Table 3. Cost of processing process (traditional "A" firm)

\begin{tabular}{|c|c|c|c|c|c|c|c|c|c|c|c|}
\hline \multirow[b]{2}{*}{ Processing costs } & \multicolumn{11}{|c|}{ Value per year in $€$ (rounded, 000 ) } \\
\hline & 2003 & 2004 & 2005 & 2006 & 2007 & 2008 & 2009 & 2010 & 2011 & 2012 & Mean values \\
\hline Energy variable cost & 10,000 & 19,000 & 24,000 & 21,000 & 25,000 & 29,000 & 24,000 & 34,000 & 31,000 & 35,000 & 25,200 \\
\hline Labor variable cost & 55,000 & 52,000 & 59,000 & 51,000 & 65,000 & 68,000 & 67,000 & 68,000 & 61,000 & 62,000 & 60,800 \\
\hline Services variable cost & 80,000 & 81,000 & 108,000 & 106,000 & 45,000 & 12,000 & 104,000 & 98,000 & 78,000 & 115,000 & 82,700 \\
\hline Other variable cost & 48,000 & 49,000 & 47,000 & 68,000 & 64,000 & 67,000 & 69,000 & 48,000 & 71,000 & 80,000 & 61,100 \\
\hline Processing variable cost & 193,000 & 201,000 & 238,000 & 246,000 & 199,000 & 176,000 & 264,000 & 248,000 & 241,000 & 292,000 & 229,800 \\
\hline Processing fixed cost & 215,000 & 220,000 & 218,000 & 265,000 & 198,000 & 197,000 & 215,000 & 197,000 & 189,000 & 225,000 & 213,900 \\
\hline Processing total cost & 408,000 & 421,000 & 456,000 & 511,000 & 397,000 & 373,000 & 479,000 & 445,000 & 430,000 & 517,000 & 443,700 \\
\hline \multicolumn{12}{|l|}{ Discount rate } \\
\hline 2012 less inflation rate) & $2.06 \%$ & $2.56 \%$ & $2.86 \%$ & $2.86 \%$ & $2.56 \%$ & $2.86 \%$ & $1.36 \%$ & $3.86 \%$ & $2.96 \%$ & $1.86 \%$ & - \\
\hline \multicolumn{12}{|l|}{ Processing total } \\
\hline \multicolumn{12}{|l|}{ Industrial total } \\
\hline cost (discounted) & $1,121,000$ & $1,078,393$ & $1,129,470$ & $1,242,330$ & $1,183,117$ & $1,075,197$ & $1,374,922$ & $1,139,936$ & $1,183,048$ & $1,369,862$ & $1,189,728$ \\
\hline \multicolumn{12}{|l|}{ Total enterprise } \\
\hline cost (discounted) & $1,293,000$ & $1,228,549$ & $1,300,545$ & $1,483,997$ & $1,344,903$ & $1,179,416$ & $1,487,424$ & $1,368,537$ & $1,274,112$ & $1,457,967$ & $1,341,845$ \\
\hline Fresh meat processed $(\mathrm{kg})$ & 875,000 & 893,000 & 911,000 & 929,000 & 980,000 & $1,000,000$ & $1,020,000$ & $1,040,000$ & $1,030,000$ & $1,051,000$ & 972,900 \\
\hline \multicolumn{12}{|l|}{ Average cost fresh } \\
\hline meat $(€ / \mathrm{kg})$ processed & 1.48 & 1.38 & 1.43 & 1.60 & 1.37 & 1.18 & 1.46 & 1.32 & 1.24 & 1.39 & 1.38 \\
\hline
\end{tabular}

Source: Our processing of directly collected data 
Mattia Iotti and Giuseppe Bonazzi / American Journal of Applied Sciences 11 (9): 1492-1506, 2014

Table 4. Cost of building management (innovative "B" firm)

\begin{tabular}{|c|c|c|c|c|c|c|c|c|c|c|c|}
\hline \multirow[b]{2}{*}{ Cost of the building } & \multicolumn{11}{|c|}{ Value per year in $€$ (rounded, 000 ) } \\
\hline & 2003 & 2004 & 2005 & 2006 & 2007 & 2008 & 2009 & 2010 & 2011 & 2012 & Mean values \\
\hline $\begin{array}{l}\text { Cost of the building construction } \\
\text { (year } 2012 \text { terminal value) }\end{array}$ & $2,245,000$ & - & - & - & - & - & - & - & - & $-1,122,500$ & - \\
\hline Cost of the project of the building & 180,000 & - & - & - & - & - & - & - & - & - & - \\
\hline Energy cost & 12,000 & 12,000 & 11,000 & 15,000 & 14,000 & 17,000 & 12,000 & 9,000 & 10,000 & 13,000 & 12,500 \\
\hline Maintenance cost & - & - & 7,000 & 5,000 & 12,000 & 85,000 & 8,000 & 3,000 & - & 2,000 & 12,200 \\
\hline Interest charge & 112,000 & 97,000 & 92,000 & 99,000 & 90,000 & 88,000 & 79,000 & 76,000 & 67,000 & 56,000 & 85,600 \\
\hline Other cost & 45,000 & 54,000 & 60,000 & 18,000 & 15,000 & 32,000 & 19,000 & 15,000 & 12,000 & 14,000 & 28,400 \\
\hline Cost of the building management & 169,000 & 163,000 & 170,000 & 137,000 & 131,000 & 222,000 & 118,000 & 103,000 & 89,000 & 85,000 & 138,700 \\
\hline $\begin{array}{l}\text { Total cost of the building } \\
\text { Discount rate (BTP } 10 \text { year 2003- }\end{array}$ & $2,594,000$ & 163,000 & 170,000 & 137,000 & 131,000 & 222,000 & 118,000 & 103,000 & 89,000 & $-1,037,500$ & 268,950 \\
\hline 2012 less infl. rate) & $2.06 \%$ & $2.56 \%$ & $2.86 \%$ & $2.86 \%$ & $2.56 \%$ & $2.86 \%$ & $1.36 \%$ & $3.86 \%$ & $2.96 \%$ & $1.86 \%$ & - \\
\hline $\begin{array}{l}\text { Total discounted cost } \\
\text { of the building }\end{array}$ & $2,594,000$ & 158,931 & 160,678 & 125,887 & 118,402 & 192,806 & 108,813 & 79,013 & 70,476 & $-878,932$ & - \\
\hline
\end{tabular}

Source: Our processing of directly collected data

Table 5. Cost of plant management (innovative "B" firm)

\begin{tabular}{|c|c|c|c|c|c|c|c|c|c|c|c|}
\hline \multirow[b]{2}{*}{ Cost of the plant } & \multicolumn{11}{|c|}{ Value per year in $€$ (rounded, 000) } \\
\hline & 2003 & 2004 & 2005 & 2006 & 2007 & 2008 & 2009 & 2010 & 2011 & 2012 & Mean values \\
\hline Plant construction cost & $1,140,000$ & - & - & - & - & - & - & - & - & - & - \\
\hline Plant project cost & 35,000 & - & - & - & - & - & - & - & - & - & - \\
\hline Energy variable cost & 12,000 & 25,000 & 24,000 & 26,000 & 28,000 & 21,000 & 29,000 & 27,000 & 21,000 & 25,000 & 23,800 \\
\hline Labor variable cost & 105,000 & 110,000 & 108,000 & 120,000 & 150,000 & 145,000 & 136,000 & 158,000 & 140,000 & 135,000 & 130,700 \\
\hline Services variable cost & 65,000 & 35,000 & 78,000 & 65,000 & 102,000 & 108,000 & 94,000 & 91,000 & 89,000 & 88,000 & 81,500 \\
\hline Other variable cost & 45,000 & 58,000 & 36,000 & 59,000 & 48,000 & 65,000 & 89,000 & 45,000 & 48,000 & 42,000 & 53,500 \\
\hline Plant variable cost & 227,000 & 228,000 & 246,000 & 270,000 & 328,000 & 339,000 & 348,000 & 321,000 & 298,000 & 290,000 & 289,500 \\
\hline Labor fixed cost & 45,000 & 50,000 & 52,000 & 53,000 & 54,000 & 50,000 & 51,000 & 56,000 & 55,000 & 60,000 & 52,600 \\
\hline Services fixed cost & 48,000 & 46,000 & 45,000 & 44,000 & 42,000 & 58,000 & 55,000 & 54,000 & 51,000 & 82,000 & 52,500 \\
\hline Other fixed cost & 32,000 & 45,000 & 24,000 & 28,000 & 48,000 & 64,000 & 109,000 & 62,000 & 51,000 & 47,000 & 51,000 \\
\hline Interest charge & 57,000 & 49,000 & 47,000 & 50,000 & 46,000 & 44,000 & 40,000 & 39,000 & 34,000 & 29,000 & 43,500 \\
\hline Plant fixed cost & 182,000 & 190,000 & 168,000 & 175,000 & 190,000 & 216,000 & 255,000 & 211,000 & 191,000 & 218,000 & 199,600 \\
\hline Plant total cost & $1,584,000$ & 418,000 & 414,000 & 445,000 & 518,000 & 555,000 & 603,000 & 532,000 & 489,000 & 508,000 & 606,600 \\
\hline $\begin{array}{l}\text { Discount rate } \\
\text { (BTP } 10 \text { year 2003- }\end{array}$ & $2.06 \%$ & $2.56 \%$ & $2.86 \%$ & $2.86 \%$ & $2.56 \%$ & $2.86 \%$ & $1.36 \%$ & $3.86 \%$ & $2.96 \%$ & $1.86 \%$ & - \\
\hline 2012 less inflation rate) & $1,584,000$ & 407,566 & 391,298 & 408,903 & 468,185 & 482,015 & 556,055 & 408,106 & 387,223 & 430,359 & - \\
\hline
\end{tabular}

Source: Our processing of directly collected data

Table 6. Cost of processing process (traditional "A" firm)

\begin{tabular}{|c|c|c|c|c|c|c|c|c|c|c|c|}
\hline \multirow[b]{2}{*}{ Processing costs } & \multicolumn{11}{|c|}{ Value per year in $€$ (rounded, 000 ) } \\
\hline & 2003 & 2004 & 2005 & 2006 & 2007 & 2008 & 2009 & 2010 & 2011 & 2012 & Mean values \\
\hline Energy variable cost & 12,000 & 31,000 & 17,000 & 12,000 & 21,000 & 24,000 & 18,000 & 19,000 & 24,000 & 21,000 & 19,900 \\
\hline Labor variable cost & 48,000 & 51,000 & 48,000 & 49,000 & 55,000 & 106,000 & 51,000 & 67,000 & 72,000 & 75,000 & 62,200 \\
\hline Services variable cost & 89,000 & 91,000 & 98,000 & 78,000 & 65,000 & 68,000 & 72,000 & 76,000 & 70,000 & 77,000 & 78,400 \\
\hline Other variable cost & 55,000 & 56,000 & 108,000 & 57,000 & 42,000 & 48,000 & 49,000 & 49,000 & 75,000 & 57,000 & 59,600 \\
\hline Processing variable cost & 204,000 & 229,000 & 271,000 & 196,000 & 183,000 & 246,000 & 190,000 & 211,000 & 241,000 & 230,000 & 220,100 \\
\hline Processing fixed cost & 150,000 & 190,000 & 175,000 & 149,000 & 164,000 & 158,000 & 138,000 & 124,000 & 135,000 & 148,000 & 153,100 \\
\hline Processing total cost & 354,000 & 419,000 & 446,000 & 345,000 & 347,000 & 404,000 & 328,000 & 335,000 & 376,000 & 378,000 & 373,200 \\
\hline $\begin{array}{l}\text { Discount rate } \\
\text { (BTP } 10 \text { year 2003- }\end{array}$ & & & & & & & & & & & \\
\hline 2012 less inflation rate) & $2.06 \%$ & $2.56 \%$ & $2.86 \%$ & $2.86 \%$ & $2.56 \%$ & $2.86 \%$ & $1.36 \%$ & $3.86 \%$ & $2.96 \%$ & $1.86 \%$ & - \\
\hline $\begin{array}{l}\text { Processing total cost } \\
\text { (discounted) }\end{array}$ & 354,000 & 408,541 & 421,543 & 317,015 & 313,630 & 350,872 & 302,464 & 256,984 & 297,742 & 320,228 & 334,302 \\
\hline $\begin{array}{l}\text { Industrial total cost } \\
\text { (discounted) }\end{array}$ & $1,938,000$ & 816,108 & 812,841 & 725,918 & 781,815 & 832,887 & 858,519 & 665,091 & 684,964 & 750,586 & 886,673 \\
\hline $\begin{array}{l}\text { Total enterprise cost } \\
\text { (discounted) }\end{array}$ & $4,532,000$ & 975,039 & 973,518 & 851,805 & 900,217 & $1,025,693$ & 967,333 & 744,104 & 755,440 & $-128,345$ & $1,159,680$ \\
\hline Fresh meat processed $(\mathrm{kg})$ & 900,000 & 918,000 & 936,000 & 955,000 & 985,000 & $1,005,000$ & $1,010,000$ & $1,030,000$ & $1,020,000$ & $1,040,000$ & 979,900 \\
\hline $\begin{array}{l}\text { Average cost fresh meat } \\
(€ / \mathrm{kg}) \text { processed }\end{array}$ & 5.04 & 1.06 & 1.04 & 0.89 & 0.91 & 1.02 & 0.96 & 0.72 & 0.74 & -0.12 & 1.18 \\
\hline
\end{tabular}

Source: Our processing of directly collected data 
Table 7. Average cost analysis in the long run (LCC approach)

\begin{tabular}{|c|c|c|c|}
\hline Average cost & Firm A & Firm B & Variance \\
\hline Average cost of the building on a 10 year time series $(€ / \mathrm{kg})$ & 0,16 & 0,28 & 0,12 \\
\hline Average cost of the plant on a 10 year time series $(€ / \mathrm{kg})$ & 0,82 & 0,56 & $-0,25$ \\
\hline Average cost of the processing on a 10 year time series $(€ / \mathrm{kg})$ & 0,41 & 0,34 & $-0,07$ \\
\hline Average total cost of the firm on a 10 year time series $(€ / \mathrm{kg})$ & 1,38 & 1,18 & $-0,20$ \\
\hline
\end{tabular}

\section{DISCUSSION}

Parma ham has a productive tradition spanning 50 years. In 1963, a group of producers founded Parma Ham Consortium (Parma PDO Ham Consortium) that today manages and protects production rules, is responsible for economic policy management in the sector and supervises and ensures the respect of laws and regulations such as the protection of the name "Parma PDO ham" and its brand; Parma PDO Ham Consortium is also the guide of trade policies and has the role of enhancing the product, conducting advertising actions and fairs to assist firms. Parma PDO ham, according to EEC Regulation 2081/92 (now Regulation EC 510/06), is produced while observing production regulations issued by the Parma PDO Ham Consortium, so Parma PDO ham is obtained by processing thighs of heavy pig that must be older than nine months, weighing more than $150 \mathrm{~kg}$ and must be slaughtered "healthy, rested and fasted for at least 15 hours," as per the specification rules. The pig must be reared in the territory of 10 regions of northern and central Italy, while the production process must be done in one part of the province of Parma between the Via Emilia, at a distance of at least $5 \mathrm{~km}$ from the north, by the river Enza, to the east and by the river Stirone, from the west. Toward the south, we have a limit of production that is an altitude above sea level not exceeding $900 \mathrm{~m}$ above the sea. Parma PDO ham has a production of 9,025,769 processed hams from 150 firms. The consumption of Parma PDO ham is split between $69 \%$ for the domestic market and $31 \%$ for foreign markets (estimated turnover, respectively, of 509 and 231 million euro). In recent years, there has been an increase in consumption of Parma ham sliced and packaged in boxes for sale in the refrigerated counter. During the period from 2005 to 2012 , the increase in the number of ham sliced was equal to $83 \%$, from 627,344 to $1,149,574$ and the relative package production increased from 30.885 million in 2005 to 62.851 in 2012. The slicing process performed in the production chain makes the consumption process easier, particularly in foreign markets, where the process of slicing made at the store or directly from the consumer is not always carried out with the necessary expertise, thus penalizing the sale to the final consumer. In the current economic crisis, both in Italy and in Europe, companies that process Parma ham have difficulties because of the reduced spending power of consumers and must be very careful to keep the costs of production while ensuring the high level of quality in the production of Parma ham as required by the production disciplinary guidelines. The European Community has implemented a strategy of diversification of farm production in order to achieve a better balance between supply and demand in the markets. Reg. (EC) No. $510 / 2006$ of 20 March 2006 regulates the protection of geographical indications and designations of origin for agricultural products and foodstuff. The verification of compliance with PDO rules shall be performed before selling the product by one or more competent agency and/or one or more control agency within the meaning of Article 2 of Reg. (EC) No. 882/2004; the control agency operates as a product certification institution. Istituto Parma Qualità (IPQ), linked with Istituto Nord Est Qualità (INEQ), has implemented a system that provides control and compliance requirements for origin of raw materials and production process upstream in the chain. In this system of rules and controls, the farms must put the firm code and the month of birth code on both legs in order to have the slaughter of animals with at least nine months of life; in this way, it is possible within 30 days after the birth of the pig to exclude animals born outside the territory of origin. The transfer of animals between farms should be documented, so it could be easier for the control issued on that by IPQ and INEQ. The slaughterhouse must fill out a document for each day of production with a list of all lots of animals received and the number of pigs slaughtered, codes of origin and origin. Moreover, the slaughterhouse puts on each thigh a stamp of approval attesting to the code compliance of origin, provenance and quality. The raw material arrives at the cold cuts production firm with the mark of identification and self-certification of slaughter, having a copy of the document issued by the slaughterhouse. In the research plan, the LCC model has been applied to two firms of the Parma PDO ham sector.

The firms in the sector often have difficulties related to the duration of the financial cycle because firms require large investments in start-up activity for the 
acquisition of industrial buildings, plants and equipment (Bonazzi et al., 2012). Moreover, the capital requirement is inherent to the typical production or aging period, which requires large volumes of capital and then expands the capital requirement for equipment. In fact, the cycle of aging fresh meat demands an expansion of capital requirements in order to sustain the financial cycle. Parma PDO ham processing firms need to have large amounts of capital to finance investments in capital assets (properties, plants and equipment) and working capital, even considering investment in inventories during the aging period of pork meat, from a minimum of 12 up to 24 months or longer. Sector firms use, in addition to equity, the following source of financing: Bank loans with a medium/long term, usually articulated in the technical form of a secured loan on real estate or, less frequently, as an unsecured claim, sometimes with collateral to pledge (usually on securities) or with a guarantee by signature, often by shareholders and/or a consortia of credit guarantees. These lines of credit are typically used to finance investments in properties, plants and equipment, specifically financing capital equipment. For the financing of working capital, firms prefer short-term lines of credit, such as advances on trade receivables, advances on contracts and advances on consignments of fresh pork leg to be processed. In the sector, there has, in fact, been a decrease in the number of firms associated with the Parma PDO Ham Consortium over the past decade, from 189 firms in 2003 to 150 firms in 2013, with the cessation of activities of 39 firms and among these, 11 terminations resulted in bankruptcy proceedings. The numerous instances of bankruptcy in the sector generate an interest in the analysis, which is applied to analyze the financial situation of firms and propose appropriate indicators that are predictive of crisis and enforceable by the managers of the firms. And given the difficult time in the field and also considering the differences between types of businesses in the sector of Parma ham, the article wants to compare data of two types of businesses that are no longer present in the sector. The first type consists of traditional businesses, which are generally family owned. These are companies that have generally lower investment, preferring a work based on the company's workforce, with direct contribution of the property. The second type consists of modern enterprises, often owned by large industrial groups. These companies often have invested in modern industrial plants to reduce the cost of production through the use of technologies that enable the saving of labor. To do this, the modern companies are often in debt, paying borrowing costs for banks to pay for the cost of debt needed to finance investment.

The two types of companies considered, traditional and modern, carry out both their production activities in compliance with the product specifications of Parma PDO ham. However, the organization of work and the level of investment for these two types of companies are different from each other and may have a different level of cost. This level of cost may be different, especially when calculated over the long term, taking into account the diversity of investments made and the weight of the financial burden as well as differences in the incidence of labor costs. The analysis of the data confirms that there are two significant types of firms. Traditional firms (type A) have higher production costs; this is due to increased plant management costs and higher costs of raw material processing, although with lower costs of property management. This is because the building structures are not new, therefore amortization are reduced. Innovative firms (type B), even though characterized by higher costs related to real estate phase, have lower plant management costs and lower costs of raw material processing. In fact, the efficiency of production management allows these companies to reduce production costs. The analysis shows that firms with high investment to improve the efficiency of production have lower long-term costs in processing; these companies have made investments in plant and machinery to increase productivity per hour, reducing the use of direct labor in the production lines. Innovative firms, in fact, even if they have invested in the initial phase of the firm's cycle, are able to gain efficiency in the production cycle as a result of the investments made in order to reduce production costs in the long run. These firms (firm B) gain advantage of cost leadership and operate with competitive advantage over their competitors. In fact, these innovative firms have lower production costs in the long run if compared with traditional firms (firm A). The analysis has interest even considering that the obtained result would not be issued considering only a short term analyis approach, but it is necessary to extend the analysis to the whole life of the plant, in order to achieve the correct results about cost absorption, even to manage correctly the firm in the long period, applying a strategic planning approach. 


\section{CONCLUSION}

The LCC approach can be a useful analytical tool of convenience to the creation and management of investments. The application of the LCC model has generally been confined to the analysis of the cost of use, throughout the useful life, of a product or a building. The LCC model has demonstrated its usefulness in the research even when it is applied in the case of analysis of enterprise management to quantify the cost of production. This analysis, when there are high investments in the initial phase of production and therefore high capital intensity, should be conducted with reference to the long-run period. In the case of the transformation of Parma PDO ham, the high initial investments in facilities and equipment and even the long aging time give importance to an analysis of long-run cost that could be carried out applying LCC model. The analysis showed, in business cases, that the conduct of investments that improve the technology and reduce the cost of production generates greater convenience and a lower total cost of production in the long run, even considering the financial and amortization costs determined by the initial investment. This type of analysis has two elements of novelty: First, the LCC approach is not applied to the analysis of a single good or service such as a plant or a building, which is what frequently appears, but is used to quantify the cost of industrial production, such as Parma PDO ham; second, the analysis is applied to a sector with high capital intensity of typical food production, showing that even in this type of industry, it is useful to make investment decisions while taking into account the convenience of long periods. In fact, research has shown that, for a given level of production, a firm that has made an initial investment in equipment and technology has a lower cost of production in the long run in the Parma PDO ham sector. The research, however, has its limits, which may be the subject of future research. In fact, the number of companies analyzed is reduced and so the research can be extended to a larger sample, even in other sectors or other countries. Again, it could be useful to consider in greater depth the analysis of the cost of the use of equity capital, to see how the choices of equity capital affect the cost of production and the convenience of transformation in the long run. In fact, the analysis of the LCC model, if it is made ex ante, presents the basic assumptions that are the result of estimates; at the same time, there is the a priori quantification of the discount rate and the estimated duration of the useful life of investments in fixed capital. It therefore becomes necessary to have constant revisions of estimated data in order to verify the goodness of ongoing forecasts. In this context, further research can be related to the construction of simulation models and risk management scenarios related to the application of the LCC model in the long run.

\section{ACKNOWLEDGEMENT}

This study is a result of the full collaboration of all the authors. However M. Iotti wrote paragraphs Material and Methods, Results, Conclusion while G. Bonazzi wrote paragraphs Introduction, Discussion.

\section{RERERENCES}

Al Omiri, M. and C. Drury, 2007. A survey of factors influencing the choice of product costing systems in UK organizations. Manage. Account. Res., 18: 399424. DOI: $10.1016 /$ j.mar.2007.02.002

Argyris, C. and R.S. Kaplan, 1994. Implementing new knowledge: The case of activity based costing. Account. Horizons, 8: 83-105.

Atkinson, A.A. and R. Kaplan, 1998. Advanced Management Accounting. 3rd Edn., Prentice-Hall, New York, ISBN-10: 0132622882, pp: 798.

Artto, K.A., 1994. Life cycle cost concept and methodologies. J. Cost Manage., 8: 51-64.

Asiedu, Y. and P. Gu, 1998. Product life cycle cost analysis: State of the art review. Int. J. Product. Res., 36: 893-908. DOI: 10.1080/002075498193444

Askarany, D. and M. Smith, 2003. The relationship between technological innovation, activity-based costing and business size. Inform. Sci., 1: 865-882.

Bjornenak, T., 1997. Diffusion and accounting: The case of ABC in Norway. Manage. Account. Res., 8: 3-17. DOI: 10.1006/mare.1996.0031

Boer, G., 1974. Direct Costing and Contribution Accounting. 1st Edn., John Wiley and Sons, New York.

Bonazzi, G. and M. Iotti, 2014. Agricultural cooperative firms: Budgetary adjustments and analysis of credit access applying scoring systems. Am. J. Applied Sci., 11: 1181-1192.

Bonazzi, G., M. Iotti and F. Paduano, 2012. Valutazioni di convenienza e di sostenibilità per le imprese del comparto del Prosciutto di Parma Dop: Un'analisi attraverso l'applicazione di indici economici e finanziari. Rivista di Econ. Agraria, 2: 61-98.

Cardinaels, E., F. Roodhooft and L. Warlop, 2004. The value of activity based costing in competitive pricing decisions. J. Manage. Account. Res., 16: 133-148. DOI: $10.2308 /$ jmar.2004.16.1.133 
Cobb, I., J. Innes and F. Mitchell, 1993. Activity-based costing problems: The British experience. Adv. Manage. Account., 12: 63-83.

Cooper, R., 1990. ABC: A need not an option. Accountancy, 1: 86-88.

Cooper, R. and R.S. Kaplan, 1991. Profit priorities from activity based costing. Harvard Bus. Rev., 69: 130-135.

Cooper, R. and R.S. Kaplan, 1992. Activity-based systems: Measuring the costs of resource usage. Account. Horizon, 6: 1-13.

Cooper, R. and R.S. Kaplan, 1999. The Design of Cost Management Systems. 2nd Edn., Illustrated, Prentice Hall, International, Upper Saddle River, ISBN-10: 0135704170, pp: 536.

Costa, M. and G. Guzzo, 2013. Fair value accounting versus historical cost accounting: A theoretical framework for judgment in financial crisis. Corporate ownership Control, 11: 146-152.

Debnath, S. and S.K. Bose, 2014. Exploring full cost accounting approach to evaluate cost of MSW services in India. Resources, Conservat. Recycl., 83: 87-95. DOI: 10.1016/j.resconrec.2013.12.007

Dolinsky, L.R. and T.E. Vollman, 1991. Transactionbased overhead considerations for product design. Cost Manage., 1: 7-19.

Dimitrios, G. and M. Aristomenis, 2005. An environmental decision support system based on a multidimensional prototype. J. Comput. Sci., 1: 225231. DOI: 10.3844 jessp.2005.225.231

Drury, C. and M. Tayles, 2005. Explicating the design of overhead absorption procedures in UK organizations. British Account. Rev., 37: 47-84.

El-Said, K.M., 2008. Cost analysis of a system with preventive maintenance by using the kolmogorov's forward equations method. Am. J. Applied Sci., 5: 405-410. DOI: 10.3844/ajassp.2008.405.410

Fabrycky, W.J. and B.S. Blanchard, 1991. Life-Cycle Cost and Economic Analysis. 1st Edn., Illustrated, Prentice Hall, Englewood Cliffs, ISBN-10: 0135383234, pp: 384.

Hedeşiu, D., S. Popescu and A. Petruş, 2012. Generic structure for quality costs in life cycle approach. Quality-Access Success, 13: 161-174.

Iotti, M. and G. Bonazzi, 2007. La valutazione degli investimenti: Un approfondimento attraverso l'analisi Life Cycle Cost (LCC) nell'impresa agraria. Ann. Fac. Medic. Vet. di Parma, 27: 321-344.
Iotti, M. and G. Bonazzi, 2014. Tomato processing firms' management: A comparative application of economic and financial analyses. Am. J. Applied Sci., 11: 1135-1151. DOI: 10.3844/ajassp.2014.1135.1151

Kallunki, J.P. and H. Silvola, 2008. The effect of organizational life cycle stage on the use of activitybased costing. Manage. Account. Res., 19: 62-79. DOI: 10.1016/j.mar.2007.08.002

Kaplan, R.S., 1988. One cost system isn't enough. Harvard Bus. Rev., 7: 61-66.

Korpi, E. and T. Ala-Risku, 2008. Life cycle costing: A review of published case studies. Managerial Audit. J., 23: 240-261. DOI: 10.1108/02686900810857703

Mizsey, P., L. Delgado and T. Benko, 2009. Comparison of environmental impact and external cost assessment method. Int. J. Life Cycle Assessment, 14: 665-675. DOI: $10.1007 / \mathrm{s} 11367-009-0098-0$

Norris, G.A., 2001. Integrating life cycle costing analysis and life cycle assessment. Int. J. Life Cycle Assessment, 6: 79-87.

Pong, C. and F. Mitchell, 2006. Full costing versus variable costing: Does the choice still matter. An empirical exploration of UK manufacturing companies 1988-2002. British Account. Rev., 38: 131-148. DOI: 10.1016/j.bar.2005.09.003

Rabino, S. and A. Wright, 1993. Accelerated product introductions and emerging managerial accounting perspectives: Implications for marketing managers in the technology sector. J. Product. Innovat. Manage., 4: 126-135. DOI: 10.1016/0737-6782(93)90004-A

Rebitzer, G. and B. Seuring, 2003. Methodology and application of life cycle costing. Int. J. Life Cycle Assessment, 8: 41-53. DOI: 10.1007/BF02978436

Rebitzer, G. and D. Hunkeler, 2004. Towards a code of practice for LCC: Update on the progress of the SETAC LCC Working Group. SETAG Globe, USA.

Schiffauerova, J.J. and B.G. Dale, 2006. A review of research on cost of quality models best practices. Int. J. Quality Reliability Manage., 23: 647-669. DOI: $10.1108 / 02656710610672470$

Shapiro, K.G., 2001. Incorporating costs in LCA. Int. J. Life Cycle Assessment. 6: 121-133.

Shim, E. and A. Stagliano, 1997. A survey of US manufacturers on implementation of ABC. J. Cost Manage., 12: 39-41.

Solli, C. and M. Reenaas, 2009. Life cycle assessment of wood-based heating in Norway. Int. J. Life Cycle Assessment, 14: 517-528. DOI: 10.1007/s11367-009-0086-4 
Srivastava, S.K., 2008. Towards estimating cost of quality in supply chains. Total Quality Manag. Bus. $\begin{array}{lll}\text { Excellence, } & 19: & 193-208 .\end{array}$ 10.1080/14783360701600605

Tysseland, B.E., 2008. Life cycle cost based procurement decisions: A case study of Norwegian defence procurement projects. Int. J. Project Manage., $26: \quad 366-375 . \quad$ DOI: 10.1016/j.ijproman.2007.09.005

Vazakidis, A., I. Karagiannis and A. Tsialta, 2010. Activity-based costing in the public sector. J. Soc. Sci., 6: 376-382. DOI: $10.3844 /$ jssp.2010.376.382
Vijaya, S., A.N. Ma and Y.M. Choo, 2009. A gate to gate assessment of environmental performance for production of crude palm kernel oil using life cycle assessment approach. Am. J. Environ. Sci., 5: 267272. DOI: 10.3844/ajessp.2009.267.272

Yoshikawa, T., J. Innes and F. Mitchell, 1994. Functional analysis of activity-based cost information. Cost Manage., 3: 40-48. 